\title{
NÂNG CAO HIỆU QUẢ CÔNG TÁC QUẢN LÝ HỌC SINH SINH VIÊN Ở TRƯỜnG ĐẠI HỌC TÂN TRÀO TRONG GIAI ĐOẠN HIỆN NAY
}

Enhancing effectiveness of student management at Tan Trao University in current stage

ThS. Lê Thị Thu Hà*

\section{TÓM TẮT}

Công tác học sinh sinh viên được xác định là một trong những nhiệm vụ trọng tâm, chủ yếu góp phần quan trọng vào việc nâng cao chất lượng đào tạo nguồn nhân lực ở các trường Đại học hiện nay. Ý thức được điều đó, trong những năm qua, trường Đại học Tân Trào đã không ngừng đổi mới nội dung, hình thức tổ chức công tác quản lý học sinh sinh viên. Những kết quả đạt được trong công tác quản lý học sinh sinh viên của trường Đại học Tân Trào đã góp phần không nhỏ vào việc thực hiện sứ mạng đào tạo nguồn nhân lực chất lượng cao phục vụ sự phát triển kinh tế - xã hội của tỉnh Tuyên Quang và các tỉnh lân cận trong khu vực.

Từ khóa: hiệu quả, công tác quản lý, học sinh sinh viên, quy chế, giải pháp

\section{ABSTRACT}

Student affair activity is identified as one of the key tasks, mainly contribute significantly to improving the quality of human resource training in the universities today. Aware of that, in recent years, the University of Tan Trao has constantly renewed the content and form of organization of the management students. The achieved results in the management students of the Tan Trao University has contributed significantly to the implementation of the mission of training highquality human resources to serve the development of economic - social development of Tuyen Quang province and neighbour provinces in the region.

Key words: Effect, Management, Students ,Regulations, Solutions

\section{Đặt vấn đề}

Trước yêu cầu của sự nghiệp công nghiệp hoá, hiện đại hoá đất nước hiện nay, việc đổi mới, nâng cao chất lượng đào tạo nguồn nhân lực đang trở thành vấn đề cấp bách. Trong những năm gần đây, Bộ Giáo dục và Đào tạo, các tổ chức quản lý giáo dục đặc biệt quan tâm tới công tác học sinh sinh viên (HSSV), hàng loạt những quy định, quy chế trong công tác HSSV được sửa đổi và ban hành nhằm nâng cao chất lượng quản lý, giáo dục HSSV đáp ứng yêu cầu của việc cung cấp nguồn nhân lực trong thời kỳ mới.

\footnotetext{
* Trường Đại học Tân Trào
}

Trường Đại học Tân Trào là cơ sở đào tạo Đại học thuộc hệ thống giáo dục quốc dân, là đơn vị sự nghiệp công lập trực thuộc Ủy ban nhân dân tỉnh Tuyên Quang, chịu sự quản lý nhà nước về giáo dục của Bộ Giáo dục và Đào tạo, là cơ sở giáo dục Đại học góp phần đào tạo nguồn nhân lực chất lượng cao phục vụ sự phát triển kinh tế - xã hội của tỉnh Tuyên Quang và các tỉnh lân cận trong khu vực. Trong những năm gần đây, cùng với đổi mới nội dung, chương trình, phương pháp giảng dạy - giáo dục, việc đổi mới phương thức và nội dung công tác HSSV được nhà trường xác định là một trong những nhiệm vụ trọng tâm. 


\section{Cơ sở khoa học của công tác quản} lý học sinh sinh viên

\subsection{Cơ sở lý luận của công tác quản lý hoc sinh sinh viên}

Quản lý là sự tác động liên tục có tổ chức, có định hướng của chủ thể (người quản lý, tổ chức quản lý) lên khách thể (đối tượng quản lý) về các mặt chính trị, văn hoá, xã hội, kinh tế... bằng một hệ thống các quy định, các chính sách, các nguyên tắc, phương pháp và biện pháp cụ thể nhằm tạo ra môi trường và điều kiện cho sự phát triển của đối tượng. Nói một cách khái quát: Quản lý là quá trình tác động có mục đích, có kế hoạch, hợp qui luật của chủ thể quản lý đến khách thể quản lý nhằm đạt tới các mục tiêu đề ra.

Quản lý HSSV là quá trình tác động có mục đích, có kế hoạch của hệ thống tổ chức quản lý HSSV thông qua các quy định, quy chế, các chính sách và bằng các phương pháp, biện pháp cụ thể, với những nội dung cụ thể nhằm đạt được các mục đích, yêu cầu của công tác HSSV.

Nội dung công tác quản lý HSSV trong trường Đại học, Cao đẳng bao gồm: Công tác tổ chức hành chính (tiếp nhận thí sinh trúng tuyển vào học; sắp xếp bố trí vào các lớp HSSV; chỉ định Ban cán sự lớp lâm thời; làm thẻ cho HSSV; tiếp nhận HSSV vào ở nội trú; thống kê, tổng hợp dữ liệu, quản lý hồ sơ của HSSV...); công tác tổ chức, quản lý hoạt động học tập và rèn luyện của HSSV (theo dõi, đánh giá ý thức học tập, rèn luyện của HSSV; phân loại, xếp loại HSSV; tổ chức thi đua, khen thưởng, kỷ luật HSSV; tổ chức "Tuần sinh hoạt công dân - HSSV"; tổ chức cho HSSV tham gia các hoạt động nghiên cứu khoa học, thi HSSV giỏi, Olympic các môn học; tổ chức triển khai công tác giáo dục tư tưởng chính trị, đạo đức, lối sống cho HSSV; tổ chức cho HSSV tham gia các hoạt động văn hoá, văn nghệ và các hoạt động ngoài giờ lên lớp khác; tổ chức đối thoại định kỳ giữa Hiệu trưởng nhà trường với HSSV; theo dõi công tác phát triển Đảng trong HSSV; tổ chức tư vấn học tập, nghề nghiệp, việc làm cho HSSV ...); công tác y tế, thể thao; thực hiện các chế độ, chính sách đối với HSSV; thực hiện công tác an ninh chính trị, trật tự, an toàn, phòng chống tội phạm và các tệ nạn xã hội; thực hiện công tác quản lý HSSV nội trú, ngoại trú...

Hệ thống tổ chức, quản lý công tác HSSV trong trường Đại học, Cao đẳng gồm có Hiệu trưởng (Hiệu phó phụ trách công tác HSSV), đơn vị phụ trách công tác HSSV, giáo viên chủ nhiệm (cố vấn học tập, trợ lý) và lớp HSSV.

Muốn quản lý HSSV tốt, trước tiên người quản lý phải được đào tạo các kiến thức cơ bản về lĩnh vực này một cách có hệ thống, nắm được các quy luật khách quan về sự phát triển tâm lý, sinh lý của HSSV, biết vận dụng các qui luật kinh tế trong việc động viên khuyến khích HSSV... Bên cạnh đó, người làm công tác quản lý HSSV còn phải biết và tạo ra, duy trì môi trường sư phạm mà ở đó mọi thành viên tham gia công tác HSSV cùng hợp tác để hoàn thành mục tiêu đào tạo đã đề ra.

\subsection{Co sở pháp lý của công tác quản lý}

\section{hoc sinh sinh viên}

Công tác HSSV là một trong những nhiệm vụ trọng tâm, chủ yếu trong toàn bộ quá trình tổ chức đào tạo ở các trường Đại học, Cao đẳng, Trung cấp chuyên nghiệp. Xác định rõ tầm quan trọng, ý nghĩa của công tác HSSV, Đảng và Nhà nước rất quan tâm tới công tác HSSV. Cùng với sự chỉ đạo thay đổi Luật giáo dục cho phù hợp với thực tiễn giáo dục và sự phát triển của kinh tế xã hội, Chính phủ đã ban hành Nghị định số 85/2003/NĐ-CP ngày 18/7/2003 quy định về chức năng, nhiệm vụ, quyền hạn và cơ cấu tổ chức của Bộ Giáo 
dục - Đào tạo và Bộ trưởng Bộ Giáo dục - Đào tạo đã ra quyết định số 4778/QĐ - BGD\&ĐT TCCB ngày 8/9/2003 về việc qui định chức năng nhiệm vụ của các tổ chức giúp Bộ trưởng thực hiện chức năng quản lý nhà nước thuộc Bộ Giáo dục - Đào tạo theo quy định tại Nghị định trên của Chính phủ, trong đó có Vụ Công tác học sinh, sinh viên.

Sau khi có quyết định của Chính phủ, các trường đã chủ động kiện toàn bộ máy phụ trách công tác HSSV theo hướng tập trung vào một đầu mối trên cơ sở sáp nhập các bộ phận làm công tác chính trị, công tác sinh viên thành phòng Công tác chính trị - sinh viên, phòng Quản lý sinh viên hoặc phòng Công tác HSSV. Bộ Giáo dục và Đào tạo cũng đã ban hành hàng loạt các văn bản quy định và hướng dẫn công tác HSSV làm căn cứ pháp lý cho các trường tổ chức quản lý và triển khai công tác HSSV một cách thống nhất và có hiệu quả như: Quy chế học sinh, sinh viên các trường Đại học, Cao đẳng và Trung cấp chuyên nghiệp hệ chính quy (kèm theo Quyết định số 42/2007/QĐ-BGDĐT ngày 13 tháng 8 năm 2007 của Bộ truoơng Bộ Giáo dục và Đào tạo); Quy định về công tác giáo dục phẩm chất chính trị, đạo đức, lối sống cho học sinh, sinh viên trong các Đại học, Học viện, trường Đại học, Cao đẳng và Trung cấp chuyên nghiệp (kèm theo Quyết định số 50/2007/QĐ-BGDĐT ngày 29 tháng 8 năm 2007 của Bộ trưởng Bộ Giáo dục và Đào tạo); Quy chế đánh giá kết quả rèn luyện của học sinh, sinh viên các cơ sở giáo dục Đại học và trường Trung cấp chuyên nghiệp hệ chính quy (kèm theo Quyêt định số 60/2007/QĐ-BGDĐT ngày 16 tháng 10 năm 2007 của Bộ trương Bộ Giáo dục và Đào tạo) và rất nhiều các quy định, hướng dẫn về chế độ miễn giảm học phí, trợ cấp ưu đãi, vay vốn tín dụng...
2. Thực trạng công tác quản lý học sinh sinh viên ở trường Đại học Tân Trào hiện nay

\subsection{Một số nét về truờng Đại học}

\section{Tân Trào}

Trường Đại học Tân Trào được thành lập ngày 14 tháng 8 năm 2013 (Quyết định số 1404/QĐ-TTg ngày 14 tháng 8 năm 2013 của Thủ tướng Chính phủ) trên cơ sở nâng cấp trường Cao đẳng Tuyên Quang; là trường Đại học công lập, đào tạo đa ngành, đa lĩnh vực; là cơ sở nghiên cứu khoa học, ứng dụng và chuyển giao công nghệ của tỉnh Tuyên Quang và một số tỉnh lân cận.

Tính đến tháng 12 năm 2015, nhà trường có gần 300 cán bộ, giảng viên, nhân viên (Tiến sỹ: 12; Thạc sỹ: 159; đang học sau Đại học: 38 ; đang làm nghiên cứu sinh trong và ngoài nước: 48) và gần 5000 HSSV.

Trường Đại học Tân Trào có nhiệm vụ đào tạo các loại hình giáo viên Mầm non, Tiểu học, THCS, THPT; cán bộ các ngành NôngLâm-Ngư nghiệp, Kinh tế và Quản trị kinh doanh trình độ Cao đẳng, Đại học; liên kết, hợp tác với các cơ sở giáo dục Đại học khác theo quy định của pháp luật; $\mathrm{NCKH}$ và chuyển giao KHCN phục vụ cho sự phát triển kinh tế xã hội.

2.2. Một số nét về phòng Quản lý sinh viên trường Đại học Tân Trào

Phòng Quản lý sinh viên trường Đại học Tân Trào tiền thân là bộ phận quản lý HSSV thuộc Phòng Tổ chức - Chính trị. Hiện tại, phòng có 16 cán bộ, giảng viên. Trong đó: Nam: 07 đ/c; Nữ: 09 đ/c. Chuyên môn: Thạc sỹ: 05 đ/c; Cử nhân: 07 đ/c; trình độ khác: 04 d/c.

Phòng có chức năng, nhiệm vụ: Tổ chức tiếp nhận thí sinh trúng tuyển vào học theo quy định của Bộ Giáo dục và Đào tạo và nhà trường; thống kê, tổng hợp dữ liệu và quản lý 
hồ sơ của HSSV; đánh giá, tổng hợp kết quả rèn luyện, khen thưởng của HSSV; tổ chức "Tuần sinh hoạt công dân HSSV"; tổ chức công tác giáo dục chính trị tư tưởng, đạo đức, lối sống cho HSSV; tổ chức các hoạt động văn hóa văn nghệ, các hoạt động ngoài giờ lên lớp khác cho HSSV; tổ chức thực hiện các chế độ chính sách của Nhà nước quy định đối với HSSV về học bổng, trợ cấp xã hội, tín dụng đào tạo và các chế độ khác có liên quan đến HSSV; quản lý HSSV nội, ngoại trú; tuyên truyền, phổ biến, giáo dục pháp luật về an toàn giao thông, phòng chống tội phạm ma túy, mại dâm, HIV/AIDS và các hoạt động khác có liên quan đến HSSV.

\subsection{Thục trạng công tác quản lý HSSV} của truò̀ng Đại học Tân Trào

2.3.1. Công tác giáo dục chính trị, tu tương, đạo đức, lối sống

Trong những năm qua, thực hiện "Quy chế học sinh, sinh viên các trường Đại học, Cao đẳng, Trung cấp chuyên nghiệp hệ chính quy" do Bộ Giáo dục và Đào tạo ban hành, với sự nỗ lực, cố gắng toàn diện của nhà trường, công tác giáo dục tư tưởng, chính trị, đạo đức, lối sống cho HSSV của nhà trường đã thu được những kết quả tốt đẹp. Đa số HSSV có nhận thức đúng đắn về mục tiêu đào tạo, có lập trường tư tưởng chính trị vững vàng, có ý thức kỷ luật, có đạo đức, lối sống lành mạnh. Nhà trường đã triển khai tốt các hình thức và biện pháp giáo dục chính trị, tư tưởng, đạo đức, lối sống đối với HSSV như: tổ chức "Tuần giáo dục công dân học sinh, sinh viên" đầu khóa, đầu năm, cuối khóa; tổ chức các hoạt động phong trào như: phong trào tình nguyện của thanh niên; tham gia đảm bảo an toàn giao thông; giữ gìn an ninh, trật tự trên địa bàn trường đóng, phong trào hiến máu nhân đạo, các hoạt động văn hóa, văn nghệ, thể dục thể thao...
2.3.2. Phong trào học tập, nghiên cứu khoa hoc của HSSV

Đa số HSSV có ý thức và động cơ học tập đúng đắn, cần cù, chịu khó khắc phục khó khăn vươn lên trong học tập, việc học tập, thi cử đã có nhiều chuyến biến tích cực, kết quả đào tạo, bồi dưỡng của nhà trường ngày càng đi vào chiều sâu, thực chất, đánh giá đúng chất lượng dạy học và giáo dục của nhà trường.

Nhà trường đã thành lập Trung tâm Tin học - Ngoại ngữ nhằm đáp ứng nhu cầu học tập, bồi dưỡng, nâng cao trình độ của HSSV. Bộ môn Tâm lý - Giáo dục đào tạo và cấp chứng chỉ Công tác Đội cho HSSV. Nhà trường còn liên kết với các cơ sở giáo dục dạy và cấp chứng chỉ nghiệp vụ nấu ăn cho học sinh sinh viên ngành Mầm non. Do vậy, HSSV khi ra trường đã đáp ứng được yêu cầu chuẩn đầu ra về Tin học, Ngoại ngữ, Công tác Đội và nghiệp vụ nấu ăn góp phần nâng cao chất lượng đào tạo của nhà trường nói chung, đáp ứng được yêu cầu ngày càng cao của xã hội.

Bốn năm trở lại đây, trường Đại học Tân Trào đã tổ chức cho học sinh sinh viên tham gia thi Olimpic Toán, Vật lý, Hóa học toàn quốc. Nhà trường đã dành được nhiều giải thưởng cao trong khối các trường Đại học, $\mathrm{CaO}$ đẳng toàn quốc.

Định kỳ hai năm một lần, nhà trường tổ chức Hội thi Nghiệp vụ sư phạm giỏi cấp trường. Hội thi đã thu hút được đông đảo HSSV tham gia. Trên cơ sở hạt nhân Hội thi cấp trường, nhà trường đã thành lập Đoàn HSSV tham gia Hội giao lưu sư phạm cụm Trung Bắc do khối các trường $\mathrm{Cao}$ đẳng, Đại học cụm Trung bắc tổ chức và đã giành được nhiều giải thưởng cao.

2.3.3. Tổ chức thực hiện các chế độ, chính sách đối với $H S S V$

Đầu năm học, nhà trường giao cho phòng Quản lý HSSV chủ trì, phối hợp với các 
đơn vị, đoàn thể tổ chức cho HSSV học tập các nội dung cơ bản của "Tuần sinh hoạt công dân HSSV", trong đó hướng dẫn HSSV khóa mới các văn bản thực hiện chế độ chính sách. Việc thực hiện chế độ chính sách đối với HSSV như trợ cấp xã hội, học bổng khuyến khích học tập, trợ cấp ưu đãi, vay vốn tín dụng đào tạo, miễn giảm học phí... Vì vậy được thực hiện đúng quy định, không để xảy ra sai sót, ách tắc, đảm bảo đúng và đủ mọi quyền lợi của HSSV.

Ngoài các chế độ chính sách theo quy định chung của Nhà nước, trường Đại học Tân Trào còn thực hiện nghiêm túc Nghị quyết 34/2013/NQ-HĐND ngày 12/12/2013 của Hội đồng nhân dân tỉnh Tuyên Quang về cơ chế, chính sách thu hút giảng viên trình độ cao và khuyến khích sinh viên cho trường Đại học Tân Trào, trong đó tập trung vào các chính sách hỗ trợ miễn giảm học phí, hỗ trợ tiền thuê nhà ở, hỗ trợ học bổng khuyến khích...

\subsubsection{Công tác quản lý học sinh $\sinh$} viên nội, ngoại trú

Khu nội trú của nhà trường có khoảng 1.200 chỗ ở.Nhà trường có bộ phận quản lý HSSV nội trú chuyên trách trực thuộc phòng Quản lý sinh viên và có 1 ban tự quản của Đoàn thanh niên để tham gia quản lý HSSV nội trú. Công tác quản lý HSSV nội trú của nhà trường được thực hiện đúng Quy chế quản lý HSSV nội trú của Bộ GD\&ĐT. Tại khu nội trú, học sinh sinh viên được phục vụ ăn uống tại Nhà ăn tập thể. Ngoài giờ học, các em có thể tham gia các hoạt động thể thao như bóng đá, bóng bàn, cầu lông, bóng chuyền, tập thể hình... tại Trung tâm thể dục thể thao của nhà trường với đầy đủ các phương tiện kỹ thuật.

Để quản lý HSSV ngoại trú, nhà trường đã phối kết hợp chặt chẽ với các cơ quan chức năng, các đoàn thể, chính quyền, nhân dân địa phương nơi trường đóng, giáo viên chủ nhiệm và ban cán sự các lớp. Tổ chức cho HSSV ngoại trú đăng ký tạm trú tạm vắng. Phòng Quản lý sinh viên thường xuyên phối hợp với lực lượng an ninh khu vực kiểm tra việc thực hiện nền nếp, quy định nơi cư trú của HSSV. Định kỳ tổ chức đối thoại với HSSV để nắm bắt diễn biến tư tưởng, những khó khăn, thuận lợi trong học tập cũng như trong cuộc sống của HSSV, qua đó kịp thời đề xuất các giải pháp nâng cao hiệu quả công tác quản lý HSSV.

\subsubsection{Việc tổ chức các hoạt động phong} trào cho học sinh sinh viên

Trường Đại học Tân Trào luôn nhận thức sâu sắc: Muốn nâng cao chất lượng đào tạo toàn diện cần đặc biệt chú trọng và quan tâm đến việc tổ chức các hoạt động phong trào của HSSV. Từ nhận thức đó, trong những năm qua nhà trường đã có nhiều hình thức và biện pháp sáng tạo, phù hợp, hiệu quả để đẩy mạnh các hoạt động văn hoá, văn nghệ, thể thao và các hoạt động xã hội trong nhà trường, cụ thể như: tổ chức tốt hoạt động văn hoá, văn nghệ, thể thao nhân kỷ niệm các ngày lễ lớn, tham gia đầy đủ, tích cực với tinh thần trách nhiệm cao các hoạt động xã hội, phong trào thanh niên tình nguyện, hiến máu nhân đạo, đền ơn đáp nghĩa... do nhà trường, các cấp, các ngành phát động.

\subsubsection{Công tác phát triển Đảng trong} hoc sinh, sinh viên

Trong nhiều năm qua, công tác phát triển Đảng trong HSSV luôn được Đảng uỷ nhà trường quan tâm, chăm lo. Trong từng nhiệm kỳ, từng năm học, Đảng uỷ đều có những nghị quyết chuyên đề về công tác phát triển Đảng trong HSSV và đã có nhiều biện pháp tổ chức thực hiện phù hợp với tình hình thực tế của nhà trường để kết nạp được những HSSV tiêu biểu. Từ năm 2010 đến nay, Đoàn thanh niên cộng sản Hồ Chí Minh bồi dưỡng, giới thiệu cho Đảng bộ được 159 Đoàn viên ưu tú để bồi 
dưỡng phát triển Đảng, Đảng bộ đã kết nạp được $08 \mathrm{HSSV}$ vào Đảng Cộng sản Việt Nam.

\subsection{Một số tồn tại trong công tác quản} lý họ sinh, sinh viên

Trong những năm qua nhà trường đã tích cực triển khai thực hiện các văn bản quy định của Bộ Giáo dục và Đào tạo về công tác HSSV, tuy nhiên trong quá trình thực hiện vẫn còn nhiều hạn chế. Cụ thể là: số HSSV đạt điểm rèn luyện từ loại Tốt trở lên chiếm tỷ lệ chưa cao, nhiều tiêu chí đặt ra trong phiếu đánh giá kết quả rèn luyện HSSV chưa phù hợp, việc theo dõi kiểm tra của hệ thống ban cán sự lớp, giáo viên chủ nhiệm chưa chặt chẽ. Việc tổ chức các hoạt động nhằm tập hợp HSSV ngoại trú chưa được thực hiện, vẫn còn tình trạng buông lỏng quản lý đối với HSSV ngoại trú. Cơ sở vật chất trong khu nội trú chưa đảm bảo nhu cầu sinh hoạt của HSSV, nhà ăn tập thể chưa phát huy được hiệu quả...

Nhà trường đã chú trọng tới việc đầu tư cơ sở vật chất trang thiết bị phục vụ cho công tác giảng dạy, nghiên cứu khoa học của cán bộ, giáo viên và HSSV, tuy nhiên do hạn chế về nguồn ngân sách nên số lượng đầu sách cho thư viện chưa đáp ứng đủ nhu cầu của việc học tập, nghiên cứu. Nhà trường đã có văn bản hướng dẫn $\mathrm{SV}$ tham gia nghiên cứu khoa học và xây dựng các tiêu chí khen thưởng cho $\mathrm{SV}$ tham gia nghiên cứu khoa học, nhưng tới nay chưa có công trình nghiên cứu của HSSV được nghiệm thu. HSSV chưa phát huy được tính sáng tạo trong học tập theo phương pháp giảng dạy mới, việc học tập vẫn còn trong tình trạng thụ động.

Phòng công tác HSSV, Hội sinh viên chưa xây dựng được các câu lạc bộ, các mô hình học thuật để tạo điều kiện giúp đỡ HSSV trong học tập, rèn luyện. Sự phối hợp giữa các phòng, khoa, giáo viên chủ nhiệm lớp với phòng Công tác HSSV chưa thật nhịp nhàng.
Một bộ phận HSSV còn thiếu trung thực trong học tập và thi cử, một số chưa có hoài bão, lý tưởng, một bộ phận có biểu hiện của lối sống hưởng thụ, đua đòi, chưa thực sự tự giác, tích cực trong học tập, rèn luyện.

\section{Một số giải pháp, kiến nghị nhằm} nâng cao hiệu quả công tác quản lý học sinh sinh viên ở trường Đại học Tân Trào

\subsection{Giải pháp}

Để thực hiện mục tiêu đào tạo nguồn nhân lực chất lượng cao thì việc nâng cao hiệu quả công tác quản lý HSSV được nhà trường xác định là một trong những nhiệm vụ trọng tâm. Muốn vậy nhà trường cần tập trung thực hiện những giải pháp sau:

Một là, tăng cuờng giáo dục tư tương chính trị, đạo đức, hình thành nhân cách, lối sống cho HSSV

Nâng cao chất lượng giảng dạy, học tập các môn khoa học Mác - Lê nin, tư tưởng Hồ Chí Minh trong nhà trường. Tổ chức thi Olympic các môn học, nghiên cứu khoa học, hội thi nghiệp vụ sư phạm giỏi. Kịp thời tuyên dương, khen thưởng HSSV đạt thành tích cao trong học tập và nghiên cứu khoa học.

Tiếp tục triển khai có hiệu quả Quy chế đánh giá kết quả rèn luyện của HSSV. Xây dựng phiếu đánh giá kết quả rèn luyện của HSSV sát với tình hình cụ thể của nhà trường. Để quản lý HSSV chặt chẽ, đánh giá chính xác, công bằng và khách quan, cán bộ quản lý HSSV phối hợp chặt chẽ với nhiều bộ phận để nắm bắt các thông tin về việc chấp hành của HSSV. Tổ chức tốt hệ thống cán bộ lớp ngay từ đầu năm học, thường xuyên tập huấn bồi dưỡng nâng cao ý thức trách nhiệm của cán bộ lớp.

Xây dựng quy định chặt chẽ về việc sử dụng thẻ $\mathrm{HSSV}$, đeo thẻ trong nhà trường và giảng đường, xuất trình thẻ khi thi. 
Hai là, nâng cao hiệu quả công tác quản lý HSSV nội, ngoại trú

Nhà trường cần huy động mọi nguồn lực để nâng cấp, xây mới Kí túc xá HSSV đáp ứng nhu cầu nhà ở của các em. Nâng cao điều kiện phục vụ sinh hoạt về điện nước, đảm bảo an ninh trật tự nhằm thu hút $\mathrm{HSSV}$ vào ở trong khu Nội trú.

Tổ chức các phong trào tự quản trong HSSV, hướng các hoạt động tự quản của HSSV vào phong trào thi đua làm xanh, sạch đẹp nhà trường, khu KTX, xây dựng phòng ở kiểu mẫu. Xây dựng quỹ khen thưởng trong khu KTX, đưa nội dung xây dựng phòng ở sạch đẹp vào nội dung đánh giá kết quả rèn luyện.

Đẩy mạnh các hoạt động văn hoá, văn nghệ, thể dục thể thao, lấy phong trào thể dục thể thao để tập hợp HSSV nội trú, hướng HSSV nội trú vào các hoạt động lành mạnh. Đổi mới hoạt động dịch vụ tại khu nội trú.

Phòng Quản lý sinh viên cần phân công cán bộ phụ trách về công tác HSSV ngoại trú, phối hợp chặt chẽ với chính quyền và công an địa phương, các gia đình có HSSV ở trọ để cùng quản lý HSSV. Định kỳ tổ chức Hội nghị giao ban với chính quyền, địa phương nơi có HSSV ở ngoại trú.

Thực hiện thống nhất việc lấy ý kiến nhận xét về HSSV ngoại trú theo học kỳ, năm học của công an khu vực nơi HSSV ngoại trú.

Triển khai các hoạt động nhằm tập hợp HSSV ngoại trú, giáo dục, tuyên truyền HSSV có biện pháp phòng ngừa, ngăn chặn các tệ nạn xã hội, xây dựng các tiêu chí để phân loại HSSV ngoại trú.

Ba là, xây dụng và triển khai các tiêu chí trong nhà truờng, đảm bảo an ninh trật tụ, an toàn và phòng chống các vấn đề tệ nạn $\boldsymbol{x} \tilde{a} \boldsymbol{h} \hat{o} i$

Xây dựng tiêu chí nhà trường đảm bảo an ninh trật tự và an toàn, nhà trường văn hoá theo tiêu chuẩn quy định của Bộ Giáo dục và Đào tạo.

Tăng cường tuyên truyền giáo dục pháp luật cho HSSV bằng nhiều hình thức: phát thanh tuyên truyền, phát tờ rơi, các cuộc thi tìm hiểu...

Tiếp tục làm tốt công tác kiểm tra, gây dựng các phong trào giúp bạn, hòm thư tố giác các tệ nạn xã hội trong học đường.

Bốn là, tạo các điều kiện cần thiết để HSSV tham gia nghiên cứu khoa học, phát huy tính chủ động sáng tạo của tuổi trẻ.

Khác với đào tạo ở phổ thông, chất lượng đào tạo ở bậc cao đẳng, Đại học không chỉ phụ thuộc vào việc giảng dạy - học tập của thầy và trò trên giảng đường mà còn phụ thuộc vào việc hướng dẫn các sinh viên tự học, tự nghiên cứu, tham gia vào các hoạt động học thuật ngoại khoá. Việc tổ chức các phong trào học thuật nhằm thu hút HSSV tích cực học tập, nghiên cứu khoa học góp phần nâng cao chất lượng đào tạo của trường. Từ ý tưởng trên, trong công tác HSSV cần xây dựng các mô hình câu lạc bộ học thuật theo các chuyên ngành cho HSSV phù hợp với thực tế nhà trường.

\subsection{Kiến nghị}

Bộ Giáo dục và Đào tạo cần có văn bản kiến nghị với Bộ Nội vụ nghiên cứu ban hành quy định về tuyển dụng công chức là HSSV, cần quan tâm đến kết quả rèn luyện của HSSV. Bởi đây là kết quả phấn đấu trưởng thành của HSSV trên rất nhiều lĩnh vực hoạt động.

Cần có sự điều chỉnh nội dung và khung điểm trong phiếu điểm rèn luyện HSSV cho phù hợp điều kiện từng nhà trường.

Các công văn về chế độ của HSSV cũng như các văn bản chỉ đạo hiện nay cần được hệ thống hoá thành cuốn sổ tay công tác HSSV để thuận tiện cho việc đối chiếu kiểm tra, thực hiện. 
Nhà trường cần đầu tư thêm kinh phí cho các hoạt động của HSSV; nâng cấp, xây dựng mới khu nội trú đáp ứng yêu cầu sinh hoạt của HSSV.
Phòng Quản lý sinh viên cần chủ động phối hợp với đoàn thanh niên thành lập các câu lạc bộ học thuật, câu lạc bộ văn nghệ, thể thao...

\section{TÀI LIỆU THAM KHẢO}

1. Báo cáo tổng kết chương trình công tác học sinh, sinh viên các trường Đại học, Cao đẳng và Trung cấp chuyên nghiệp giai đoạn 2009-2012, Hà Nội, T7 năm 2012.

2. Quản lý Nhà nước về Giáo dục\&Đào tạo,Trường cán bộ quản lý giáo dục và đào tạo, Hà Nội 2005.

3. Hướng dẫn thực hiện chế độ học bổng khuyến khích học tập và Trợ cấp xã hội đối với học sinh sinh viên các trường đào tạo công lập (Ban hành kèm theoThông tu liên tịch số 53/1998/TTLT/BGDĐT-BTC-BLĐTBXH ngày 25 tháng 8 năm 1998).

4. Quy chế học sinh, sinh viên các trường Đại học, Cao đẳng và Trung cấp chuyên nghiệp hệ chính quy (Ban hành kèm theo Quyết định số 42/2007/QĐ-BGDĐT ngày 13 tháng 8 năm 2007 của Bộ trưởng Bộ Giáo dục và Đào tạo).

5. Quy định về công tác giáo dục phẩm chất chính trị, đạo đức, lối sống cho học sinh, sinh viên trong các Đại học, học viện, trường Đại học, cao đẳng và trung cấp chuyên nghiệp (Ban hànhkèm theo Quyết định số 50/2007/QĐ-BGDĐT ngày 29 tháng 8 năm 2007 của Bộ trưởng Bộ Giáo dục và Đào tạo).

6. Quychế đánh giá kết quả rèn luyện của học sinh, sinh viên các cơ sở giáo dục Đại học và trường trung cấp chuyên nghiệp hệ chính quy (Ban hànhkèm theo Quyết định số 60/2007/QĐBGDĐT ngày 16 tháng 10 năm 2007 của Bộ trưởng Bộ Giáo dục và Đào tạo).

7. Quy chếNgoại trú của học sinh, sinh viên các trường Đại học , cao đẳng, trung cấp chuyên nghiệp hệ chính quy (Ban hành kèm theo Thông tu số 27/2009/TT-BGDĐT ngày 19 tháng 10 năm 2009 của Bộ trương Bộ Giáo dục và Đào tạo).

8. Quy chế đánh giá kết quả rèn luyện của người học được đào tạo trình độ Đại học hệ chính quy(Ban hành kèm theo Thông tu số 16/2015/TT-BGDĐT Ngày 12 tháng 8năm 2015 của Bộ trương Bộ Giáo dục và Đào tạo).

9. Văn kiện Hội nghị lần thứ II Ban chấp hành Trung ương Đảng khoá VIII, Nhà xuất bản Chính trị Quốc gia, Hà nội 1997. 